\title{
A Slacks-Based Measure of Efficiency of Electric Arc Furnace Activity with Undesirable Outputs
}

\author{
Hao Zhang, Xiang Su, Shilun Ge \\ Economics \& Management School, Jiangsu University of Science and Technology, Zhenjiang, China. \\ Email:haozh168@yahoo.com.cn
}

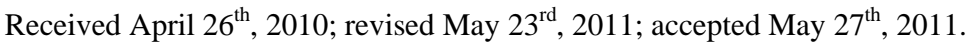

\begin{abstract}
Efficiency reflects a scenario of higher quality product with fewer resource inputs and less pollution discharge. In terms of a manufacturing firm, it means a win-win strategy in both economic and environmental categories. The paper extends the Electric Arc Furnace (EAF) activity management by taking pollution discharge as undesirable outputs. After reviewing relative undesirable outputs DEA literatures and comparing their advantages and shortcomings, the current paper introduces SBM models to treat undesirable outputs and then measures the efficiency of each EAF activity. Based on resources input and activity quantity output and undesirable outputs, the DEA model can evaluate the efficiency of EAF activity. By the input-output combination, the sensitivity analysis is done. At last, the paper demonstrates the application of efficiency measurement in EAF activity of an iron \& steel enterprise. The result implies objectivity, accuracy and practicability of the activity analysis and valuation method based on SBM-Undesirable model.
\end{abstract}

Keywords: Electric Arc Furnace, Slacks-based Measure, Activity Management, Undesirable Outputs

\section{Introduction}

Nearly $50 \%$ of the steel production these days is by Electric Arc Furnace (EAF) route, which uses high-current electric arcs to melt steel scrap and convert it into liquid steel of a specified chemical composition and temperature. The major charge material of electric-arc steelmaking is scrap steel, and its availability at low cost and proper quality is essential. Moreover, the electric power used in EAF operation, however, is high, at 360 to 600 kilowatt-hours per ton of steel, and the installed power system is substantial.

Activity-based costing (ABC) determines cost drivers as activity measures to allocate overhead costs more accurately than traditional cost systems. In contrast, activity-based management is not only concerned with allocating overhead costs more precisely but tries also to identify and improve inefficient activities. In this sense activity-based management is the more comprehensive concept. In identifying inefficient activities it is often necessary to have reference activities for comparison. These activities may correspond to other decision making units (DMUs) such as other companies or divisions. Also, one might want to compare different observations over time corresponding to a single organizational unit. We investigate the use of data envelopment analysis (DEA) to benchmark activities. DEA provides each DMU with an efficiency score that has to be viewed as its relative efficiency in the set of all DMUs involved in the benchmarking. We identify the pros and cons of DEA as being applied to benchmark activities.

In the production theory approach, pollutants (also called undesirable outputs) and desirable outputs are assumed to be generated in the same production process. So the paper extends the activity management by taking pollution discharge as an undesirable output.

The objective of this work is to provide a quantitative model for EAF activity-based management (ABM) with undesirable outputs. The model developed is based on data envelopment analysis, an established operational research technique for productivity and efficiency determinations. Activity centers are considered as decisionmaking units whose efficiencies are determined by solution of the ABM/DEA model. ABM follows from activity-based costing whereby $\mathrm{ABC}$ information is employed in improvement and cost reduction plan. A real case study of an iron and steel factory is used to illustrate the application of the model.

\section{Literature}

Data envelopment analysis (DEA), developed by Char- 
nes, Cooper, \& Rhodes (1978), is a well-established nonparametric approach used to evaluate the relative efficiency of a set of comparable entities called decision making units (DMUs) with multiple inputs and outputs [1]. Numerous DEA theoretical and application studies have been reported [2,3]. Efficiency is relatively measured meaning that efficiency of DMUs is subject to analysis according to each other is measured. Following the analysis, the DMU are grouped into two sets as efficient and inefficient. The envelop line formed by the efficient DMUs is named as efficient frontier, and it covers the inefficient DMUs as what an envelopment does. Thus, this property gives the name of analysis. The efficiency performance of the activity management has been a critical research stream that draws considerable attention [4-7]. Most studies about the application of DEAbased models to activity management performance measurement assume that the reduction of undesirable outputs (or inputs) and the increase of desirable outputs are proportional. This implies that the slacks in inputs and outputs are not accounted for when activity management performance is evaluated. Although the resulting efficiency measures have some good theoretical properties, the assumption often leads to a lot of comparable entities having the same efficiency scores of 1 and hence difficult in making useful comparisons.

Therefore, it is meaningful to incorporate the input excesses and output shortfalls into DEA-based models in measuring activity management performance. Moreover, most studies utilized the DEA approach as a tool for evaluating accomplishments in the past. Although the evaluation results highlight the status of the operational performance and are helpful for planning future activities for improving the performance, the ex post facto evaluation might be a little late for an unsuccessful unit to find its weaknesses and make the appropriate amendments.

There is one difficulty in doing an objective evaluation of the performance of DMUs. The difficulty is how to treat undesirable outputs jointly produced with desirable outputs. Traditional literature only values the desirable and simply ignores the undesirable. However, ignorance of the undesirable is equal to saying that they have no value in the final evaluation and may present misleading results. It is therefore necessary to credit DMUs for their provision of desirables and penalize them for their provision of undesirables. In the presence of undesirable outputs, however, technologies with more good (desirable) outputs and less bad (undesirable) outputs relative to less input resources should be recognized as efficient. In the DEA literature, several authors have proposed methods for this purpose [8-10].

In this research, we employ Slack Based Measurement (SBM) for the involved DEA models [11]. In contrast to the radial models, CCR and BCC which are based on the proportional reduction (enlargement) of input (output) vectors and which do not take account of slacks, the SBM deals directly with input excess and output shortfall. SBM is non-radial and deals with input/output slacks directly. The SBM returns an efficiency measure between 0 and 1 and gives unity if and only if the DMU concerned is on the frontiers of the production possibility set with no input/output slacks. In that respect, SBM differs from traditional radial measures of efficiency that do not take account of the existence of slacks [12].

The main purpose of this paper is to propose one slacks-based efficiency measures for modeling EAF activity management performance.

In this research, we evaluate the performance of the EAF activity management based on the input-output data via slacks-based DEA model. The results can be used for planning management activities in advance to enhance the activities operational efficiency and increase a high discriminating power for measuring activity management performance. The rest of this paper is organized as follows: Section 2, we introduce the method of slacks-based efficiency measures in DEA by taking pollution discharge as an undesirable output, then in Section 3 we discuss the input and output factors used to measure the EAF activity efficiency. Sections 4 and 5 we utilize the case of EAF, and finally, the results are discussed and some conclusions drawn from the discussion.

\section{Proposed SBM DEA Model}

The SBM DEA model projects each unit onto the efficient frontier and has many attractive features, among them, units-invariance. The original SBM DEA model computes the ratio of the average inputs reduction to the average output increase. Minimizing that ratio implies the simultaneous pursuit of improvements in both inputs and outputs. It is, therefore, a non-oriented model. It is also non-radial, i.e., it does not force the input and outputs to be improved uniformly or equal-proportionally, letting the maximum possible improvement in each dimension be computed by the model. In addition, the SBM efficiency score leaves no input or output slack unaccounted, i.e. all possible improvements are exhausted and properly taken into account in the objective function.

In total, all the above explorations have effectively broadened our understanding of efficiency evaluation of DMUs. Based on the above, the model of this paper is constructed.

Suppose that there are n DMUs(decision making units) each having three factors: inputs, good outputs and bad(undesirable)outputs, as represented by three vectors $x \in R^{m}, \quad y^{g} \in R^{s 1}$ and $y^{b} \in R^{s 2}$, respectively. We 
define the matrices $X 、 Y^{g}$ and $Y^{b}$ as follows:

$X=\left[x_{1}, \cdots, x_{n}\right] \in R^{m \times n} \quad, \quad Y^{g}=\left[y_{1}^{g}, \cdots, y_{n}^{g}\right] \in R^{s 1 \times n}$, $Y^{b}=\left[y_{1}^{b}, \cdots, y_{n}^{b}\right] \in R^{s 2 \times n}$, We assume $X>0, \quad Y^{g}>0$ and $\bar{Y}^{b}>0$. The production possibility set $(P)$ is defined by:

$$
P=\left\{\left(x, y^{g}, y^{b}\right) \mid x \geq X \lambda, y^{g} \leq Y^{g} \lambda, y^{b} \geq Y^{b} \lambda, \lambda \geq 0\right\}
$$

Definition 1 ( Efficient DMU ) :

A $\operatorname{DMU}_{0}\left(x_{o}, y_{o}^{g}, y_{o}^{b}\right)$ is efficient in the presence of undesirable outputs if there is no vector $\left(x, y^{g}, y^{b}\right) \in P$ such that $x_{o} \geq x, y_{o}^{g} \leq y^{g}$ and $y_{o}^{b} \geq y^{b}$ with at least one strict inequality.

In accordance with this definition, we modify the SBM in Tone (2001) as follows.

$$
\begin{aligned}
& {[\mathrm{SBM}] \rho^{*}=\min } \frac{1-\frac{1}{m} \sum_{i=1}^{m} \frac{s_{i}^{-}}{x_{i 0}}}{1+\frac{1}{s_{1}+s_{2}}\left(\sum_{r=1}^{s_{1}} \frac{s_{r}^{g}}{y_{r 0}^{g}}+\sum_{r=1}^{s_{2}} \frac{s_{r}^{b}}{y_{r 0}^{b}}\right)} \\
& \text { s.t. } x_{0}=X \lambda+s^{-} \\
& y_{0}^{g}=Y^{g} \lambda-s^{g} \\
& y_{0}^{b}=Y^{b} \lambda+s^{b} \\
& s^{-} \geq 0, s^{g} \geq 0, s^{b} \geq 0, \lambda \geq 0
\end{aligned}
$$

The objective function strictly decreases with respect to $s_{i}^{-}(\forall i), s_{r}^{g}(\forall r)$ and $s_{r}^{b}(\forall r)$ and the objective value satisfies $0 \leq \rho^{*} \leq 1$. Let an optimal solution of the above program be $\left(\lambda^{*}, s^{-^{*}}, s^{g^{*}}, s^{b^{*}}\right)$.

Then, we have:

Theorem 1 The $\mathrm{DMU}_{0}$ is efficient in the presence of undesirable outputs if and only if $\rho^{*}=1$, i.e., $s^{-^{*}}=0$, $s^{g^{*}}=0$ and $s^{b^{*}}=0$.

If the $\mathrm{DMU}_{0}$ is inefficient, i.e., $\rho^{*}<1$, it can be improved and become efficient by deleting the excesses in inputs and bad outputs, and augmenting the shortfalls in good outputs via the following SBM-projection:

$$
x_{o} \leftarrow x_{o}-s^{-^{*}}, y_{o}^{g} \leftarrow y_{o}^{g}+s^{g^{*}}, y_{o}^{b} \leftarrow y_{o}^{b}-s^{b^{*}} .
$$

Using the transformation by Charnes and Cooper (1962), we arrive at an equivalent linear program in $t, \Lambda, S^{-}, S^{g}$ and $S^{b}$ as displayed below.

$$
[L P] \tau^{*}=\min t-\frac{1}{m} \sum_{i=1}^{m} \frac{S_{i}^{-}}{x_{i o}}
$$

Subject to

$$
\begin{aligned}
& 1=t+\frac{1}{s_{1}+s_{2}}\left(\sum_{r=1}^{s_{1}} \frac{S_{r}^{g}}{y_{r o}^{g}}+\sum_{r=1}^{s_{2}} \frac{S_{r}^{b}}{y_{r o}^{b}}\right) \\
& x_{o} t=X \Lambda+S^{-} \\
& y_{o}^{g} t=Y^{g} \Lambda-S^{g}
\end{aligned}
$$

$$
\begin{aligned}
& y_{0}^{b} t=Y^{b} \Lambda+S^{b} \\
& S^{-} \geq 0, S^{g} \geq 0, \\
& S^{b} \geq 0, \Lambda \geq 0, t \geq 0 .
\end{aligned}
$$

Let an optimal solution of [LP] be

$\left(t^{*}, \Lambda^{*}, S^{-*}, S^{g^{*}}, S^{b^{*}}\right)$. Then we have an optimal solution of $[\mathrm{SBM}]$ as defined by

$$
\begin{aligned}
& \rho^{*}=\tau^{*}, \lambda^{*}=\Lambda^{*} / t^{*}, s^{-*}=S^{-*} / t^{*}, \\
& s^{g^{*}}=S^{g^{*}} / t^{*}, s^{b^{*}}=S^{b^{*}} / t^{*} .
\end{aligned}
$$

The existence of $\left(t^{*}, \Lambda^{*}, S^{-*}, S^{g^{*}}, S^{b^{*}}\right)$ with $t^{*}>0$ is guaranteed by [LP].

\section{Analytic Procedure and Selection of Input and Output Items}

\subsection{Analytic Procedure}

The analytic procedure for SBM-DEA mainly includes three parts: first, the assessment objects should be defined and selected. Second, relevant and appropriate input, desirable and undesirable output items are determined, in order to facilitate the relative efficiency evaluation for evaluation object. Third, based on the application of DEA model, the experimental results will be evaluated. Therefore this paper will take the above analytic procedure as the basis for DEA analysis.

\subsection{The Selection of Input and Output Items}

Without loss of generality, this paper will take electric arc furnace (EAF) smelting activity efficiency analysis of iron and steel enterprise as example. Solid substances used in the electric arc furnace (scrap, ferrous alloys, iron slurry) are melted predominantly by electrical energy which is inputted via the electrodes, as well as by fossil energies in the presence of oxygen. Electric arc furnaces have currently capacity of up 200 tones; the duration of heat is in the region of 1 to 4 hours. Owing to their high energy input, modern electric furnaces produces considerable quantities of smoke and waste gas.

EAF activity efficiency is influenced by raw materials, management, technology, operations, equipment status and other factors.

So according to the applicability, simplicity and comparability of selection index, the input and output indexes are determined.

The input data should more objectively reflect the actual situation of EAF operations. The most basic inputs of EAF activity are iron and steel material consumption, power consumption and energy consumption; and outputs include desirable outputs and undesirable outputs. The desirable outputs include passing rate of molten steel, and the undesirable outputs include wastewater emis- 
sions and dust emissions.

Index calculation methods are as follows:

Ferrous charges consumption:

$$
M s i=\frac{(M i+M w)}{M e s}
$$

In formula: $M s i$ - ferrous charges consumption, $\mathrm{kg} / \mathrm{t}$; $M i$ - Pig iron consumption, kg; $M w$ - Scrap steel consumption, kg; Mes - qualified steel yield, t.

Process energy consumption:

$$
E u=\frac{(E s+E p-E o)}{M e s}
$$

In formula: $E u$ - process unit standard coal consumption, kgce/t; $E s$ - fuel consumption, kgce; $E p$ - power consumption, kgce; $E o$ - Surplus energy recovery, kgce; Mes - qualified steel yield, $t$.

General power consumption:

$$
E c=\frac{(E c p)}{M e s}
$$

Ecp - power consumption, kwh; Mes - qualified steel yield, t.

Liquid steel qualified rate:

$$
\text { Se }=\frac{M-M d}{M}
$$

In formula: $S e$ - liquid steel qualified rate, \%; $M$ - raw material weight, t; $M d$-metal loss, $t$.

Contaminations:

$$
C l=\frac{C s l}{M s}
$$

In formula: $\mathrm{Cl}$ - unit discharge amount of the main pollutant, $\mathrm{kg} / \mathrm{t}$; $\mathrm{Csl}$ - discharge amount of the main pollutant, kg; $M s$ - liquid steel annual yield, t.

In summary, the input and output items of electric arc furnace activity are shown in Table 1.

\section{Case Study}

\subsection{Data Collection}

In this paper, we analyze 15 furnace (capacity of 20 - $40 \mathrm{t}$ )

Table 1. The input and output items of electric arc furnace activity.

\begin{tabular}{ccc}
\hline & Items & Unit \\
\hline & Steel scrap consumption & $\mathrm{kg} / \mathrm{t}$ \\
Inputs & Power consumption & $\mathrm{kWh} / \mathrm{t}$ \\
& Process energy consumption & $\mathrm{kgce} / \mathrm{t}$ \\
Output & Passing rate of molten steel & $\%$ \\
Undesirable & Wastewater emissions & $\mathrm{m}^{3} / \mathrm{t}$ \\
Outputs & Dust emissions & $\mathrm{kg} / \mathrm{t}$ \\
\hline
\end{tabular}

in the September, 2009 in an iron \& steel enterprise. The original input and output data was obtained from the production system. The main data information is shown in Table 2.

\subsection{Results and Discussion}

According to the above model, we use the linear programming software (lingo 9.0) to calculate platform, the result is shown in Table 3.

According to the SBM-DEA model (Table 3): In inspected objects, only 4 DMU (DMU5, DMU6, DMU8, DMU13 account for 26\%) are integrated effective, the synthetic validity $(\theta)$ is 0.729 , it means the operation performance of the EAF activity system has already achieved certain level. Six DMUs (DMU1, DMU5, DMU6, DMU8, DMU10, DMU13 account for 40\%) is technically effective and the synthetic validity $(\varphi)$ is 0.776 . That is to say, the technical validity is relatively high. From tab 3, 2 DMUs (DMU1, DMU10 account for 13\%) are only technical validity, not integrated effective.

It means these EAFs have already played its best technical level. But due to lack of organization of production and the impact of the order, these DMUS have failed to increase production scale.

Other 9 DMUs have put too much resource and produced much pollutants, resulting in relatively noneffective. Therefore raw materials, energy, and various cost control must be considered in the future. By using reasonable charge structure, increasing alloying elements recovery, and reducing refining time and pollutants emissions, better efficiency can be gotten to enhance the EAF activity operational performance.

We applied the SBM-DEA model, with variable returns to scale, to evaluate the technical efficiency of each EAF activity. Also, the scale efficiency can be derived by the ratio of overall efficiency to technical efficiency. Table 3 summarizes the results. The four overall efficient EAFs have the technical efficiency and the scale efficiency. In particular, (DMU1, DMU10) has the technical efficiency scores equal to 1 while their scale efficiency scores are less than 1 . It should adjust their scales of operation to improve their scale efficiencies as well as overall efficiencies. A DMU may be scale inefficient if it exceeds the most productive scale size (thus experiencing decreasing returns to scale), or if it is smaller than the most productive scale size (thus having not taken the full advantage of increasing returns to scale). Indeed, most of the inefficient EAFs present increasing returns to scale that can increase the scales to effectively improve their efficiencies. In particular, seven of the scale inefficient EAFs (i.e., DMU 2, 3, 4 7, 9, 11, 12, 14 and 15) had their scale efficiency scores higher than the technical efficiency scores, respectively. This implies that the overall 
Table 2. Statistical analysis of input-output data.

\begin{tabular}{ccrrrr}
\hline & Items & Max & Min & Mean \\
\hline \multirow{2}{*}{ Inputs } & Steel scrap consumption & 1120 & 920 & 1032.40 & 71.93 \\
& Power consumption & 321 & 232 & 275.40 & 31.17 \\
Outputs & Process energy consumption & 127 & 66 & 101.67 & 18.61 \\
& Passing rate of molten steel & 100 & 97 & 99 & 0.845 \\
Undesirable Outputs & Wastewater emissions & 1.3 & 0.4 & 0.91 & 0.277 \\
& Dust emissions & 4 & 1.9 & 2.8 \\
\hline
\end{tabular}

Table 3. The efficiency and returns to scale for DMUs.

\begin{tabular}{|c|c|c|c|c|c|c|c|}
\hline Number & $\begin{array}{c}\text { Overall } \\
\text { efficiency }\end{array}$ & $\begin{array}{l}\text { Technical } \\
\text { efficiency }\end{array}$ & Scale efficiency & Returns to scale & Reference set & $\begin{array}{l}\text { Reference } \\
\text { times }\end{array}$ & Rank \\
\hline 1 & 0.748 & 1.000 & 0.748 & irs & 1 & & \\
\hline 2 & 0.638 & 0.645 & 0.990 & irs & 5 & & \\
\hline 3 & 0.559 & 0.571 & 0.980 & drs & 13 & & \\
\hline 4 & 0.580 & 0.587 & 0.989 & drs & 13 & & \\
\hline 5 & 1.000 & 1.000 & 1.000 & - & 5 & 4 & 2 \\
\hline 6 & 1.000 & 1.000 & 1.000 & - & 6 & & \\
\hline 7 & 0.645 & 0.660 & 0.978 & irs & 13 & & \\
\hline 8 & 1.000 & 1.000 & 1.000 & - & 8 & & \\
\hline 9 & 0.656 & 0.663 & 0.989 & irs & 13 & & \\
\hline 10 & 0.623 & 1.000 & 0.623 & irs & 10 & & \\
\hline 11 & 0.679 & 0.687 & 0.988 & irs & 13 & & \\
\hline 12 & 0.608 & 0.615 & 0.989 & irs & 5 & & \\
\hline 13 & 1.000 & 1.000 & 1.000 & - & 13 & 7 & 1 \\
\hline 14 & 0.642 & 0.642 & 1.000 & - & 5 & & \\
\hline 15 & 0.569 & 0.569 & 1.000 & - & 13 & & \\
\hline Mean & 0.729 & 0.776 & 0.952 & & & & \\
\hline
\end{tabular}

inefficiency is primarily due to the technical inefficiency. Only DMU 3 and 4 present the decreasing returns to scale that can decrease their scales to possibly improve their efficiencies. On the other hand, one overall inefficient $\mathrm{EAF}$ (i.e., DMUs 1 and 10) is mainly due to the scale inefficiency because their scale inefficiency scores are lower than technical efficiency scores. The technical inefficient EAF should improve their productivity and make better use of their resources.

One way for increasing their efficiency is to adjust their scales by transferring resources from EAFs operating at decreasing returns to scale to those operating at increasing returns to scale.

Taking the number 2 furnace as the example, the meaning of reference set is explained. Number 2 EAF overall efficiency is 0.638 as the SBM-DEA noneffective unit. So it must take number 5 furnace as a benchmark, adjusting the input and output to achieve the DEA effective with reference to their production units. Which is referenced more times (such as the DMU 13) is a more powerful efficiency unit.

Non-DEA efficient units do not achieve the technical efficiency is largely due to excessive investment in the number of resources. By slack variable analysis, input and output adjustment amount of the non-DEA unit is shown in Table 4.

For the slack variable analysis, there are 6 EAFs at the efficiency frontier with input and output slack variables of 0 . Among the inefficient EAFs, DMU 14 had the greatest excess in the input variable 'Steel scrap consumption'. DMU 4 had the greatest excess in the input variables 'Power consumption' and 'Dust emissions'. DMU 3 had the greatest excess in undesirable output 'Wastewater emissions'.

\section{Sensitivity Analysis}

\subsection{Input/Output Indicators Combinations}

Sensitivity analysis is a very important aspect of DEA to evaluate the robustness of the results. Since DEA is a data based analysis, any error in the data set can change the results. Sensitivity analysis has been carried out in a number of ways in the literatures. In this study, we assume that the data set is correct and precise, as it is taken from various sources. So, we have carried out the sensitivity analysis based on removal of variables one by one from the data set, and finding out the efficiency scores to check the robustness of the DEA results.

Table 5 summarizes the results of sensitivity analysis carried out to check the robustness of the results (efficiency scores).

\subsection{Efficiency Value Analysis of Different Indicators Combinations}

The efficiencies of all EAFs were calculated under each of the 3 specifications. The full list of specifications can be seen in the heading of the columns in Table 5. Table 
Table 4. Potential improvement for inefficient DMU.

\begin{tabular}{|c|c|c|c|c|c|c|}
\hline \multirow[b]{2}{*}{ Number } & \multicolumn{3}{|c|}{ inputs } & \multirow{2}{*}{$\begin{array}{c}\text { outputs }(+) \\
\text { Passing rate of } \\
\text { molten steel }\end{array}$} & \multicolumn{2}{|c|}{ Undesirable outputs(-) } \\
\hline & $\begin{array}{l}\text { Steel scrap } \\
\text { consumption }\end{array}$ & $\begin{array}{c}\text { Power } \\
\text { consumption }\end{array}$ & $\begin{array}{c}\text { Process energy } \\
\text { consumption }\end{array}$ & & $\begin{array}{l}\text { Wastewater } \\
\text { emissions }\end{array}$ & Dust emissions \\
\hline 2 & 145 & 35 & 29 & 0 & 0.4 & 0.9 \\
\hline 3 & 138 & 59 & 38 & 2 & 0.6 & 2.1 \\
\hline 4 & 30 & 83 & 60 & 1 & 0.5 & 1.0 \\
\hline 7 & 20 & 62 & 44 & 2 & 0.4 & 0.4 \\
\hline 9 & 118 & 40 & 33 & 1 & 0.5 & 0.4 \\
\hline 11 & 119 & 29 & 39 & 1 & 0.4 & 0.2 \\
\hline 12 & 128 & 74 & 38 & 1 & 0.5 & 0.6 \\
\hline 14 & 160 & 7 & 52 & 0 & 0.3 & 1.2 \\
\hline 15 & 150 & 60 & 61 & 0 & 0.3 & 1.9 \\
\hline
\end{tabular}

Table 5. Combination of different input/output indicators.

\begin{tabular}{|c|c|c|c|c|c|c|}
\hline \multirow[b]{2}{*}{ Group } & \multicolumn{3}{|c|}{ inputs } & \multirow{2}{*}{$\begin{array}{c}\text { outputs }(+) \\
\text { Passing rate of } \\
\text { molten steel }\end{array}$} & \multicolumn{2}{|c|}{ Undesirable outputs(-) } \\
\hline & $\begin{array}{l}\text { Steel scrap } \\
\text { consumption }\end{array}$ & $\begin{array}{c}\text { Power } \\
\text { consumption }\end{array}$ & $\begin{array}{l}\text { Process } \\
\text { energy consumption }\end{array}$ & & $\begin{array}{l}\text { Wastewater } \\
\text { emissions }\end{array}$ & $\begin{array}{c}\text { Dust } \\
\text { emissions }\end{array}$ \\
\hline 1 & $\checkmark$ & $\checkmark$ & $\checkmark$ & $\checkmark$ & & \\
\hline 2 & $\checkmark$ & $\checkmark$ & $\checkmark$ & $\checkmark$ & $\checkmark$ & $\checkmark$ \\
\hline 3 & $\checkmark$ & $\checkmark$ & $\checkmark$ & $\checkmark$ & $\checkmark$ & \\
\hline
\end{tabular}

Table 6. Efficiency value of different input/output indicator combinations.

\begin{tabular}{cccc}
\hline \multirow{2}{*}{ Number } & \multicolumn{3}{c}{ Overall efficiency } \\
\cline { 2 - 4 } & Group 1 & Group 2 & Group 3 \\
\hline 1 & 0.848 & 0.748 & 0.730 \\
3 & 0.780 & 0.638 & 0.653 \\
4 & 0.754 & 0.559 & 0.592 \\
5 & 0.737 & 0.580 & 0.584 \\
6 & 1.000 & 1.000 & 1.000 \\
7 & 1.000 & 1.000 & 1.000 \\
8 & 0.775 & 0.645 & 0.623 \\
9 & 1.000 & 1.000 & 1.000 \\
10 & 0.796 & 0.656 & 0.635 \\
11 & 0.831 & 0.623 & 0.661 \\
12 & 0.795 & 0.679 & 0.645 \\
13 & 0.752 & 0.608 & 0.598 \\
14 & 1.000 & 1.000 & 1.000 \\
15 & 0.796 & 0.642 & 0.677 \\
Mean & 0.728 & 0.569 & 0.599 \\
& 0.839 & 0.729 & 0.733 \\
\hline
\end{tabular}

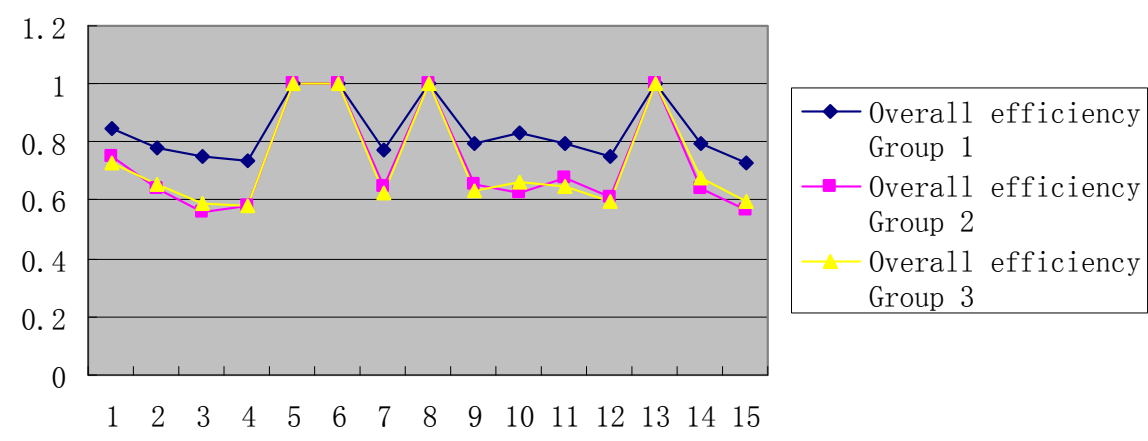

Figure 1. Changes in operating efficiency trend of various indicators combinations. 
6 shows, for each of the 15 EAFs and every specification, the efficiency score achieved.

It can be observed that, given a particular EAF, efficiency depends on the specification estimated. Visual inspection of Table 6 reveals some interesting features.

Take DMU 14 as an example, the removal of 'dust emissions' would drop the efficiency value from 0.677 to 0.642 . This shows that 'dust emissions' were the more sensitive variables than 'wastewater emissions' for the operational performance of this EAF. DMU 11 is 0.679 efficient under the Original combination 2, but only 0.645 efficient under combination 3. It is clear that this EAF activity has a strong at dust emissions.

\section{Conclusions}

Evaluation of the operational performance of EAFs is important for ensuring efficiency in the iron \& steel industry. By adopting SBM-DEA models and considering the undesirable output, iron \& steel industry can accurately assess aspects of their own performance that require improvement, and can gain an enhanced understanding of the current EAF operational status and future improvement. Here SBM-DEA analysis has provided several useful insights.

First, efficiency value analysis has established that while some major EAFs are of optimal scale, others are not.

Secondly, slack variable analysis is seen as potentially providing an understanding of how EAFs can improve their operational performance by enabling managers can focus on a limited number of variables for short-term and long-term improvement.

Thirdly, sensitivity analysis shows that the 'dust emissions' and the 'Wastewater emissions' are two undesirable output variables that have higher sensitivity with respect to EAF efficiency. Moreover DEA can be based on non-financial evaluations, it is appropriate to compare DMUs with different cost conditions.

\section{Acknowledgements}

This work was financially supported by National Natural Science Foundation of China (No. 70971056), and the Department of Science and Technology, Jiangsu Provincial People's Government (BK2009728) of the People's Republic of China.

\section{REFERENCES}

[1] A. Charnes, W. W. Cooper and E. Rhodes, "Measuring Efficiency of Decision Making Units,” European Journal of Operational Research, Vol. 2, No. 4, 1978, pp. 429-444. doi:10.1016/0377-2217(78)90138-8

[2] L. M. Seiford, "Data Envelopment Analysis: The Evolution of the State of the Art (1978-1995)," Journal of Productivity Analysis, Vol. 7, No. 2-3, 1999, pp. 99-137. doi:10.1007/BF00157037

[3] W. W. Cooper, L. M. Seiford and K. Tone, "Data Envelopment Analysis: A Comprehensive Text with Models, Applications, References, and DEA-Solver Software," Kluwer Academic, Boston, 2000.

[4] S. Mota, J. H. Benzecry and R. Y. Qassim, “A Model for the Application of Data Envelopment Analysis in Activity-based Management," International Journal of Technology Management, Vol. 17, No. 7/8, 1999, pp. 862-868. doi:10.1504/IJTM.1999.002749

[5] C. Homburg, "Using Data Envelopment Analysis to Benchmark Activities,” International Journal of Production Economics, Vol. 73, No. 1, 2001, pp. 51-58. doi:10.1016/S0925-5273(01)00194-3

[6] P. Y. Ou, Y. L. Wang and P. X. Wang, "The Application of Composite DEA in Activity Analysis and Evaluation,” Systems Engineering, Vol. 24, No. 6, 2006, pp. 52-57.

[7] P. Y. Ou and F. J. Wang, "The Resources Utilization Efficiency Evaluation of Activity Based on DEA,” Chinese Journal of Management, Vol. 6, No. 8, 2009, pp. 1061-1065.

[8] R. Fare, S. Grosskopt, C. A. K. lovell and C. Pasurka, "Multilateral Productivity Comparisons When Some Outputs are Undesirable: A Nonparametric Approach,” Review of Economics and Statistics, Vol. 71, No. 1, 1989, pp. 90-98.doi:10.2307/1928055

[9] H. Schee, "Undesirable Outputs in Efficiency Valuations," European Journal of Operational Research, Vol. 132, No. 2, 2001, pp. 400-410. doi:10.1016/S0377-2217(00)00160-0

[10] L. M. Seiford and J. Zhu, "Modeling Undesirable Factors in Efficiency Evaluation,” European Journal of Operational Research, Vol. 142, No. 1, 2002, pp. 16-20. doi:10.1016/S0377-2217(01)00293-4

[11] K. Tone, “A Slacks-Based Measure of Efficiency in Data Envelopment Analysis,” European Journal of Operational Research, Vol. 130, No. 3, 2001, pp. 498-509. doi:10.1016/S0377-2217(99)00407-5

[12] K. Tone, “A Slacks-Based Measure of Super-Efficiency in Data Envelopment Analysis," European Journal of Operational Research, Vol. 143, No. 1, 2002, pp. 32-41. doi:10.1016/S0377-2217(01)00324-1 